\title{
Produção de cebola sobre palhada a partir de mudas obtidas em bande- jas com diferentes números de células
}

\author{
Marie Y Reghin; Rosana F Otto; Jean Ricardo Olinik; Carlos Felipe S Jacoby \\ UEPG-Dep ${ }^{\text {to. }}$ Fitotecnia e Fitossanidade, 84030-900 Ponta Grossa-PR; E-mail: freghin@ convoy.com.br
}

\begin{abstract}
RESUMO
O presente experimento foi conduzido em Ponta Grossa-PR, com o objetivo de avaliar mudas de cultivares de cebola obtidas em bandejas com diferentes números de células e sua influência sobre a produção da cebola, quando em cultivo sob palhada. O experimento referente à produção de mudas foi conduzido em ambiente protegido. O delineamento experimental foi blocos casualizados, com três repetições. Os tratamentos foram distribuídos segundo esquema fatorial 4 x 3, sendo quatro cultivares (Mercedes, Bola Precoce, Crioula e Montana) e três tipos de bandejas de poliestireno expandido, com 128, 200 e 288 células. O substrato utilizado foi Plantmax® e a semeadura foi realizada em 15 de maio de 2004. As mudas foram avaliadas com 53 dias de idade para altura da parte aérea, comprimento da raiz e massa fresca e seca da parte aérea e da raiz. O experimento de campo foi conduzido sob palhada de aveia, previamente dessecada. O delineamento experimental foi blocos casualizados, com três repetições, com os seguintes tratamentos: cultivares Mercedes, Bola Precoce, Crioula e Montana, com mudas produzidas em bandejas de 128 (M1), 200 (M2) e 288 (M3) células. Oitenta e quatro dias após o transplante, foram avaliados a altura, o número de folhas e diâmetro do pseudocaule. A colheita foi realizada em diferentes datas, de acordo com a maturação das plantas, avaliando-se o rendimento e a classificação dos bulbos de acordo com o diâmetro. Na produção de mudas, os maiores valores de altura e massa fresca da parte aérea foram registrados em mudas de bandejas com 128 células, para todas as cultivares. O tamanho da muda, maior no tratamento M1, foi um importante atributo na definição de sua de qualidade, proporcionando, em campo, maior precocidade de bulbificação, maior rendimento e melhor qualidade de bulbos. Independentemente da cultivar, a produção de mudas de cebola em bandejas resultou em alta produtividade (com média de $90,7 \mathrm{t} \mathrm{ha}^{-1}$ ) e qualidade de bulbos, tendo destaque a muda M1 que apresentou rendimento acima de 77,0 $\%$ de bulbos das classes $3 \mathrm{C}(60<\varnothing<70 \mathrm{~mm})$ e $4(70<\varnothing<90 \mathrm{~mm})$.
\end{abstract}

Palavras-chave: Allium cepa L., tamanho da muda, rendimento de bulbos, classificação de bulbos, cultivo mínimo, plantio direto.

\begin{abstract}
Onion yield in no-tillage system using seedlings produced in trays with different cell numbers

The experiment was carried out in Ponta Grossa-PR, aiming to evaluate onion seedlings produced in trays with different cell numbers and their further field production under a no tillage system. Onion seedlings were produced under protected cultivation. The experimental design was completely randomized blocks, with three replications. Treatments followed a factorial scheme $4 \times 3$, with four cultivars (Mercedes, Bola Precoce, Crioula and Montana) and three types of polystyrene trays, with 128,200 and 288 cells. The substrate used was Plantmax ${ }^{\circledR}$ and seeds were sowed in May, 15. Seedlings were evaluated 53 days after sowing for length, fresh, and dry weight of upground and root material. The field trial was carried out on dry oat straw. The experimental design was completely randomized blocks, with three replications, with the following treatments: four cultivars (Mercedes, Bola Precoce, Crioula, and Montana) and three tray types; 128 (M1), 200 (M2), and 288 cells (M3). 84 days after transplanting, plant height, leaf number and neck diameter were evaluated. Plants were harvested on different days, according to maturation. Yield was evaluated and bulbs were graded by diameter into classes. In seedling production, it was observed that the highest values for onion upground length and fresh weight were obtained on seedlings produced in 128 cells to all cultivars. The largest size of the M1 seedlings was an important attribute to define quality on seedlings production. This characteristic reflected on early bulbification and higher bulb yield and quality, when compared with M2 and M3 seedlings. Independent of the cultivar, seedlings produced in trays resulted in high yield (average of $90,7 \mathrm{t} \mathrm{ha}^{-1}$ ) and high bulb quality and M1 seedlings shower strong concentration of bulbs graded into classes $3 \mathrm{C}(60<\varnothing<70 \mathrm{~mm})$ and $4(70<\varnothing<90 \mathrm{~mm})$.
\end{abstract}

Keywords: Allium cepa L., seedling size, bulb yield, bulb grading, minimum tillage, no-tillage.

\section{(Recebido para publicação em 17 de janeiro de 2006; aceito em 11 de dezembro de 2006)}

$\mathrm{N}^{\circ}$ o Brasil, a cebola é plantada desde região Sul até a região Nordeste, destacando-se os Estados de Santa Catarina, Rio Grande do Sul, São Paulo, Paraná, Bahia, Pernambuco e Minas Gerais, responsáveis pela quase totalidade da produção nacional (Boeing, 2002). No Paraná, a cebola é uma das principais culturas de subsistência para grande número de pequenos produtores das regiões de Imbituva e de Irati. Na safra 2001/2002, a área cultivada foi de 1.040 ha em Irati (Seab/Deral, 2002). No entanto, a falta de planejamento de safra e de informações técnicas sobre os sistemas de cultivo, da época adequada de plantio, cultivares mais adequadas para a região, desuniformidade das mudas na sementeira e o baixo nível de tecnologia empregado em muitas lavouras, são alguns dos fatores responsáveis pela baixa produtividade da cebola na região, de 10,7 t ha-1 (Resende et al., 2002), e baixa qualidade do produto do Estado.
Quando a cebola não é plantada por semeadura direta, o sucesso na produção de bulbos depende diretamente da qualidade da muda obtida na sementeira. No entanto, esta qualidade vem sendo afetada principalmente pelo tombamento e doenças foliares (EPAGRI, 1995). Em outros países, o sistema de venda de mudas é mais difundido, normatizado e fiscalizado. No Brasil, estamos caminhando mais acentuadamente nesta direção em algumas horta- 
liças como, por exemplo, tomate, em São Paulo e Goiás. No caso da cebola, ainda não existem produtores exclusivos de mudas. Entre as razões para isto estão a necessidade de grande quantidade de mudas para o transplante em função da alta densidade de plantas por hectare e a área de cultivo maior que a maioria das demais hortaliças. Ademais, o custo da semente de cultivares nacionais (exceto de híbridos), não tem sido elevado a ponto de o produtor procurar outras alternativas.

Em cebola, o uso de bandejas tem sido testado em casos específicos como, por exemplo, na produção de bulbinhos (Cardoso \& Costa, 1999) e na produção de mudas de cebola no verão (Vincenzo \& Tessarioli Neto, 2003). Em ambos os casos, o uso de bandejas tem sido vantajoso sobre o método convencional de produção de mudas de cebola, ou seja, a semeadura em sementeiras e posterior transplante de mudas selecionadas.

O método de cultivo que predomina no Paraná também é o da sementeira em canteiros. A semeadura é realizada predominantemente entre maio e junho. O transplante se concentra no mês de agosto, com mudas de mais de oitenta dias pós-semeadura. Portanto, o tempo para a produção de mudas é um período longo devido principalmente às temperaturas baixas que predominam nesta época, muitas vezes com ocorrência de geadas. Para manter a sanidade das mudas nesse período, a intensidade de pulverizações com defensivos tem sido cada vez maior. Observa-se pouca eficiência no processo, considerando que as sementes ficam expostas em condições muito desuniformes de solo, temperatura e chuvas. Conseqüentemente, a germinação, a emergência e o crescimento das plântulas também são irregulares, com ocorrência de doenças que causam falhas e desuniformidade nos estandes.

Uma opção à semeadura direta em canteiros é a utilização de bandejas de poliestireno expandido. O uso de bandejas é eficiente na produção, condução, transporte e plantio das mudas de hortaliças no local definitivo, já que as bandejas são leves, de fácil manuseio, comportam um número muito grande de mudas, ocupam uma área mínima e fa- cilitam o transplante de mudas com torrão (Minami, 1995). Em países como Holanda e Canadá, a produção de mudas de cebola em bandejas tem conferido maior uniformidade às mudas, evitando a competição entre plantas usualmente observada na sementeira. Além disso, não há estresse nas raízes durante o transplante (Jaime et al., 2001). Na Itália, quando se compararam três sistemas de propagação (semeadura direta, transplante de mudas provenientes de sementeira e transplante de mudas provenientes de bandejas de poliestireno expandido), o rendimento de bulbos foi maior quando as mudas foram produzidas em bandejas (Dellacecca et al. 2000). Porém, na produção de mudas o tamanho da célula é um fatores que influencia diretamente o desenvolvimento e a arquitetura do sistema radicular (Latimer, 1991). Na Flórida, as mudas produzidas em volume de célula de 4,0 $\mathrm{cm}^{3}$ produziram $16 \%$ a menos de bulbos de maior padrão do que mudas oriundas de volume de $7,1 \mathrm{~cm}^{3}$ (Leskovar \& Vavrina, 1999).

O presente trabalho teve como objetivo avaliar a influência de diferentes tipos de bandejas na produção de mudas e no seu posterior desenvolvimento em campo, incluindo os efeitos sobre o rendimento e a qualidade dos bulbos.

\section{MATERIAL E MÉTODOS}

O experimento teve a etapa de produção de mudas conduzida no Viveiro Primavera, em Ponta Grossa-PR, sob cultivo protegido com estrutura metálica em arco coberto com filme de polietileno de 120 micras. O delineamento experimental foi blocos casualizados, com três repetições. Os tratamentos foram distribuídos em esquema fatorial $4 \times 3$, sendo quatro cultivares (Mercedes, Bola Precoce, Montana e Crioula) e três tipos de bandejas de poliestireno expandido: 128 (40 $\mathrm{cm}^{3}$ por célula), $200\left(16 \mathrm{~cm}^{3}\right)$ e 288 células $\left(10 \mathrm{~cm}^{3}\right)$. O substrato utilizado nas bandejas foi Plantmax ${ }^{\circledR}$, procedendo-se a semeadura no dia 15 de maio de 2004, com duas sementes por célula e posterior desbaste após a emergência, mantendo-se uma planta por célula. Após 30 dias da semeadura, as mudas receberam adubação complementar com kristasol (15-30-15) na dose de $1 \mathrm{~g} \mathrm{~L}^{-1} \mathrm{H}_{2} \mathrm{O}$. Cinquenta e três dias após a semeadura, as mudas foram avaliadas para altura parte aérea, massa fresca e seca da parte aérea e da raiz e comprimento da raiz (após lavagem sob água corrente para retirada do substrato e secagem em papel toalha). Os valores de massa seca foram obtidos após secagem em estufa de ventilação forçada, regulada para $60^{\circ}$ C.

O experimento de campo foi conduzido na Fazenda-Escola da Universidade Estadual de Ponta Grossa (PR), localizada a $880 \mathrm{~m}$ de altitude, em solo do tipo CAMBISSOLO HÁPLICO Tb Distrófico, de textura argilosa (EMBRAPA, 1999). O delineamento experimental foi blocos casualizados, com três repetições, constando cada bloco de doze tratamentos: cultivar Mercedes, com mudas obtidas em bandejas de 128 (1), 200 (2) e 288 células (3); cutivar Bola Precoce, com mudas obtidas em bandejas de 128 (4), 200 (5) e 288 células (6); cultivar Crioula, com mudas obtidas em bandejas de 128 (7), 200 (8) e 288 células (9) e; cultivar Montana, com mudas obtidas em bandejas de 128 (10), 200 (11) e 288 células (12). As mudas obtidas nas bandejas de 128, 200 e 288 células foram denominadas de M1, M2 e M3, respectivamente.

$\mathrm{Na}$ área do experimento de campo havia, previamente, aveia dessecada e rolada. O preparo mínimo do solo constou de sulcamento manual das linhas a cada $0,40 \mathrm{~m}$, seguido de adubação com a fórmula 5-25-25, na quantidade de 50 $\mathrm{m}^{-1}$. O transplante foi realizado no dia 08 de julho de 2004, 54 dias após a semeadura. Cada parcela foi composta por quatro fileiras com 2,0 m de comprimento, com as plantas arranjadas no espaçamento $0,40 \times 0,08 \mathrm{~m}$. A cultura teve manejo da irrigação por aspersão. A adubação em cobertura foi realizada antes da bulbificação, com uréia, na quantidade de $20 \mathrm{~g} \mathrm{~m}^{-1}$. O controle de plantas daninhas foi realizado manualmente uma vez, no início do desenvolvimento vegetativo. Foram realizadas três pulverizações ao longo do ciclo com Clorotalonil $\left(400 \mathrm{~g} \mathrm{~kg}^{-1}\right)+$ Metalaxyl (80 $\mathrm{g} \mathrm{kg}^{-1}$ ) para o controle de mildio 
Tabela 1. Número de folhas, altura e massa fresca da parte aérea de mudas de cebola, em função de cultivares (Mercedes, Bola Precoce, Crioula e Montana) e do tipo da bandeja (B128= 128 células; B200= 200 células e B288=288 células). Ponta Grossa, UEPG, 2004.

\begin{tabular}{llllllllllll}
\hline & \multicolumn{2}{c}{$\mathbf{N}^{\mathbf{0}}$ de folhas } & & & \multicolumn{3}{c}{ Altura da parte aérea $(\mathbf{c m})$} & & \multicolumn{3}{c}{ Massa fresca (g planta-1) } \\
\hline Cultivar & B 128 & B 200 & B 288 & & B 128 & B 200 & B 288 & & B 128 & B 200 & B 288 \\
\hline Mercedes & $2,8 \mathrm{Aa}^{*}$ & $2,7 \mathrm{Aab}$ & $2,7 \mathrm{Aa}$ & & $23,3 \mathrm{Ab}$ & $21,0 \mathrm{ABab}$ & $19,9 \mathrm{Ba}$ & & $0,8 \mathrm{Ab}$ & $0,6 \mathrm{Ba}$ & $0,6 \mathrm{Ba}$ \\
B. Precoce & 3,0 Aa & $3,0 \mathrm{Aa}$ & $2,8 \mathrm{Aa}$ & & $27,5 \mathrm{Aa}$ & $19,9 \mathrm{Bb}$ & $17,3 \mathrm{Bab}$ & & $1,1 \mathrm{Aa}$ & $0,7 \mathrm{Ba}$ & $0,5 \mathrm{Cab}$ \\
Crioula & $3,0 \mathrm{Aa}$ & $2,3 \mathrm{Bb}$ & $2,7 \mathrm{ABa}$ & & $23,8 \mathrm{Ab}$ & $21,6 \mathrm{Aab}$ & $14,3 \mathrm{Bbc}$ & & $1,0 \mathrm{Aab}$ & $0,7 \mathrm{Ba}$ & $0,4 \mathrm{Cbc}$ \\
Montana & $3,0 \mathrm{Aa}$ & $3,0 \mathrm{Aa}$ & $2,0 \mathrm{Bb}$ & & $27,1 \mathrm{Aa}$ & $23,6 \mathrm{Ba}$ & $12,8 \mathrm{Cc}$ & & $1,0 \mathrm{Aab}$ & $0,7 \mathrm{Ba}$ & $0,3 \mathrm{Cc}$ \\
\hline
\end{tabular}

*Médias seguidas da mesma letra maiúscula na linha e minúscula na coluna não diferem significativamente entre si a $5 \%$ de probabilidade pelo teste de Tukey.

(Peronospora destructor). As características de altura, número de folhas expandidas e diâmetro do pseudocaule foram avaliadas 84 dias após o transplante, nas duas linhas centrais da parcela, usando sete plantas ao acaso. Nesta época, avaliou-se também o número de plantas que apresentavam bulbificação, em todas as plantas da parcela. Antes de proceder à colheita, foram avaliados o número total de plantas por parcela e o número de plantas com estalo e com florescimento prematuro. A colheita foi realizada de acordo com a maturação das plantas, em uma área útil de $0,5 \mathrm{~m}^{2}(1,0 \mathrm{~m}$ de comprimento e $0,5 \mathrm{~m}$ de largura), abrangendo as duas linhas centrais e totalizando 32 plantas. Os tratamentos Mercedes M1 e M2 foram colhidos em 29 de outubro; os tratamento Mercedes M3 e Bola Precoce M1 e M2, em 8 de novembro; os tratamentos Bola Precoce M3, Crioula M1 e Montana M1, em 17 de novembro e, os demais tratamentos (Crioula M2 e M3 e Montana M2 e M3), em 30 de novembro de 2004. Após a cura dos bulbos, fez-se a toalete, a contagem do número de bulbos e sua classificação de acordo com o diâmetro transversal (portaria 529 de 18 de março de 1995, MAA), como segue: classe $1(15<\varnothing<35 \mathrm{~mm}), 2(35<\varnothing<50$ $\mathrm{mm}), 3$ (50<Ø<60 mm), 3C $(60<\varnothing$ $<70 \mathrm{~mm}), 4(70<\varnothing<90 \mathrm{~mm})$ e 5 (> 90 $\mathrm{mm})$. Foi avaliada ainda a produção em peso de todas as classes. Os dados foram submetidos à análise de variância e as médias comparadas pelo teste de Tukey, a $5 \%$ de probabilidade.

\section{RESULTADOS E DISCUSSÃO}

Houve interação significativa entre cultivares e tamanho das células das bandejas onde foram produzidas as mudas para número de folhas e altura e massa fresca da parte aérea, indicando que o desenvolvimento das mudas das cultivares Mercedes, Bola Precoce, Montana e Crioula dependeu do tipo de bandeja utilizado. A bandeja com 128 células promoveu respostas positivas e significativas nas características altura e massa fresca da parte aérea em todas as cultivares (Tabela 1).

Para altura da parte aérea, as mudas produzidas em bandejas de 128 células superaram significativamente as mudas produzidas em bandejas de 200 e 288 células, para as cultivares Bola Precoce e Montana, e as mudas produzidas em bandejas de 288 células, para as cultivares Mercedes e Crioula. Já para massa fresca da parte aérea, as mudas produzidas em bandejas de 128 células superaram todos os outros tipos de mudas para todas as cultivares. Em relação ao número de folhas, houve efeito significativo do tamanho da célula apenas para a cultivar Crioula (Tabela 1). Mudas desta cultivar produzidas em bandejas com 128 células apresentaram um número de folhas significativamente maior que mudas produzidas em bandejas de 200 células, embora não tenham diferido de mudas produzidas em bandejas de 288 células (Tabela 1 ).

Nas demais características (comprimento e massa fresca da raiz, diâmetro do pseudocaule, massa seca da parte aérea e da raiz) não houve interação significativa, embora tenha sido observado efeito significativo para tipo de bandeja e cultivares isoladamente (Tabela 2). Estes resultados concordam com os obtidos por outros autores, em cebola (Leskovar \& Vavrina, 1999), e em outras espécies (Barros, 1997; Modolo \& Tessarioli Neto, 1998; Resende et al., 2003; Reghin et al., 2004). Quanto maior o volume da célula, maior o tamanho da muda e mais precocemente estará a muda apta para o transplante, característica que é altamente desejável. Por outro lado, Herison et al. (1993) observaram que o aumento do número de plântulas por célula, de uma para três em bandejas de 200 células, causou diminuição do tamanho da muda e atraso na maturidade de plantas no campo em uma semana. Nas condições do Sul, a característica de precocidade na etapa de produção de mudas é altamente relevante, pois as mudas de sementeira demoram mais de 80 dias para estarem aptas para transplante. No ambiente natural onde são desenvolvidas as sementeiras de cebola, as plantas são submetidas a amplitudes térmicas muito variáveis e às temperaturas muito baixas que predominam no período.

A uniformidade de desenvolvimento das mudas em cada tipo de bandeja foi uma das características que visualmente chamou a atenção, pois cada plântula teve o próprio espaço físico definido na bandeja e não houve efeito de competição. Além disso, o ambiente protegido propiciou a obtenção de mudas de qualidade em menor tempo, 53 dias após a semeadura. Durante o desenvolvimento das mudas, não foram observadas sintomas de ocorrência de doenças, não sendo realizada nenhuma pulverização. Essa é uma vantagem significativa, pois os produtores têm realizado pulverizações semanais quando as mudas são produzidas em sementeira.

As mudas estão no tamanho ideal para transplante quando apresentam altura da parte aérea de 15 a $20 \mathrm{~cm}$ e diâmetro de um lápis, 6 a 8 mm (Fontes \& Silva, 2002), o que normalmente é atingido entre 40 e 70 dias da semeadura. Neste experimento, as mudas produzi- 
das em bandejas de 128 e 200 células apresentaram altura acima de $20 \mathrm{~cm}$. No entanto, o diâmetro do pseudocaule foi menor do que a amplitude indicada pelos autores. Os valores observados foram maiores nas bandejas de 128 e 200 células $(3,12$ e 3,0 mm, respectivamente), diferindo significativamente do valor observado nas mudas produzidas em bandejas de 288 células, com 2,6 mm (Tabela 2).

Em campo, as plantas de todos os tratamentos, de forma geral, apresentaram grande desenvolvimento vegetativo, com média de altura de 72,3 $\mathrm{cm}, 9,5$ de folhas em média e diâmetro do pseudocaule de 18,2 mm (Tabela 3). Ainda assim, algumas diferenças foram observadas. Oitenta e quatro dias após o transplante, as plantas provenientes de mudas M1 e M2 das cultivares Crioula e Montana foram significativamente mais altas que plantas da mesma cultivar, quando utilizadas mudas M3 (Tabela 3). Para as demais cultivares, a altura de planta não foi afetada pelo número de células da bandeja onde foi produzida a muda. Não houve efeito da muda sobre o número de folhas quando a comparação foi feita somente entre mudas da mesma cultivar. Para número de folhas, as únicas diferenças significativas foram observadas entre plantas das cultivares Bola Precoce e Crioula originadas de mudas M1, que produziram um número de folhas significativamente maior que plantas da cultivar Mercedes originadas de mudas M2 e M3 (Tabela 3). Para diâmetro do pseudocaule tampouco foram observadas diferenças significativas para mudas de uma mesma cultivar (Tabela 3 ). Para esta característica, diferenciaramse significativamente apenas plantas das cultivares Crioula e Montana originadas de mudas M1, comparadas com a cultivar Mercedes provenientes de mudas M2 e M3, que foram menores que aquelas. O menor número de folhas da cultivar Mercedes pode ser justificado pela ocorrência de míldio 63 dias após o transplante. As folhas infectadas foram retiradas da planta. Para o controle, foram realizadas três aplicações consecutivas, com intervalo de dez dias de Clorotalonil (400 $\left.\mathrm{g} \mathrm{kg}^{-1}\right)+$ Metalaxyl (80 $\left.\mathrm{g} \mathrm{kg}^{-1}\right)$. O míldio afetou principalmente os tratamentos M2 e M3 da cultivar

Tabela 2. Comprimento e massa fresca da raiz, diâmetro do pseudocaule, massa seca da parte aérea e raiz de mudas de cebola, em função do tipo da bandeja (B128=128 células; B200 $=200$ células e B288 $=288$ células) e de cultivares (Mercedes, Bola Precoce, Montana e Crioula). Ponta Grossa, UEPG, 2004.

\begin{tabular}{|c|c|c|c|c|}
\hline \multirow{2}{*}{ Características } & \multicolumn{4}{|c|}{ Tipo de bandeja } \\
\hline & B 128 & \multicolumn{2}{|c|}{ B 200} & B 288 \\
\hline Comprimento da raiz $(\mathrm{cm})$ & $6,4 \mathrm{~A}$ & \multicolumn{2}{|c|}{$5,6 \mathrm{~B}$} & $4,9 \mathrm{C}$ \\
\hline Massa fresca da raiz $(\mathrm{g})$ & $0,3 \mathrm{~A}$ & \multicolumn{2}{|c|}{$0,2 \mathrm{~B}$} & $0,2 \mathrm{C}$ \\
\hline Diâmetro do pseudocaule (mm) & $3,2 \mathrm{~A}$ & \multicolumn{2}{|c|}{$3,0 \mathrm{~B}$} & $2,6 \mathrm{C}$ \\
\hline Massa seca da parte aérea $(\mathrm{g})$ & $0,1 \mathrm{~A}$ & \multicolumn{2}{|c|}{$0,1 \mathrm{~B}$} & $0,1 \mathrm{~B}$ \\
\hline Massa seca da raiz $(\mathrm{g})$ & \multicolumn{3}{|c|}{$0,2 A B$} & $0,1 \mathrm{~B}$ \\
\hline \multirow{2}{*}{ Características } & \multicolumn{4}{|c|}{ Cultivares } \\
\hline & Mercedes & Bola Precoce & Crioula & Montana \\
\hline Comprimento da raiz $(\mathrm{cm})$ & $5,1 \mathrm{~B}$ & $6,1 \mathrm{~A}$ & $5,6 \mathrm{AB}$ & $5,7 \mathrm{AB}$ \\
\hline Massa fresca da raiz $(\mathrm{g})$ & $0,2 \mathrm{~B}$ & $0,3 \mathrm{~A}$ & $0,3 \mathrm{~A}$ & $0,2 \mathrm{~B}$ \\
\hline Diâmetro do pseudocaule $(\mathrm{mm})$ & $3,2 \mathrm{~A}$ & $3,0 \mathrm{~A}$ & $3,0 \mathrm{~A}$ & $2,5 \mathrm{~B}$ \\
\hline Massa seca parte aérea (g) & $0,01 \mathrm{~A}$ & $0,1 \mathrm{~A}$ & $0,1 \mathrm{~A}$ & $0,1 \mathrm{~A}$ \\
\hline Massa seca da raiz $(\mathrm{g})$ & $0,1 \mathrm{~A}$ & $0,2 \mathrm{~A}$ & $0,2 \mathrm{~A}$ & $0,1 \mathrm{~A}$ \\
\hline
\end{tabular}

*Médias seguidas da mesma letra maiúscula na linha não diferem significativamente entre si a $5 \%$ de probabilidade pelo teste de Tukey.

Tabela 3. Altura da parte aérea, número de folhas, diâmetro do pseudocaule e porcentagem de plantas com bulbos 84 dias após o transplante. Ponta Grossa, UEPG, 2004.

\begin{tabular}{llccc}
\hline Tratamentos & Altura $(\mathbf{c m})$ & $\begin{array}{c}\text { Número de } \\
\text { folhas }\end{array}$ & Diâmetro $(\mathbf{m m})$ & $\begin{array}{c}\% \text { de } \\
\text { bulbificação }\end{array}$ \\
\hline Mercedes M1 & $81,4 \mathrm{ab}^{*}$ & $9,3 \mathrm{ab}^{*}$ & $17,9 \mathrm{abc}$ & 54,6 \\
Mercedes M2 & $71,0 \mathrm{abcd}$ & $8,2 \mathrm{~b}$ & $15,6 \mathrm{bc}$ & 38,3 \\
Mercedes M3 & $66,7 \mathrm{bcd}$ & $8,1 \mathrm{~b}$ & $15,5 \mathrm{c}$ & 35,2 \\
Bola Precoce M1 & $78,1 \mathrm{abc}$ & $10,3 \mathrm{a}$ & $20,4 \mathrm{ab}$ & 7,4 \\
Bola Precoce M2 & $73,5 \mathrm{abcd}$ & $9,8 \mathrm{ab}$ & $18,5 \mathrm{abc}$ & 0,0 \\
Bola Precoce M3 & $65,1 \mathrm{~cd}$ & $9,7 \mathrm{ab}$ & $18,1 \mathrm{abc}$ & 0,0 \\
Crioula M1 & $82,6 \mathrm{a}$ & $10,5 \mathrm{a}$ & $20,8 \mathrm{a}$ & 0,0 \\
Crioula M2 & $71,4 \mathrm{abcd}$ & $9,7 \mathrm{ab}$ & $17,8 \mathrm{abc}$ & 0,0 \\
Crioula M3 & $63,1 \mathrm{~d}$ & $8,7 \mathrm{ab}$ & $16,7 \mathrm{abc}$ & 0,0 \\
Montana M1 & $80,8 \mathrm{ab}$ & $9,7 \mathrm{ab}$ & $21,4 \mathrm{a}$ & 0,0 \\
Montana M2 & $71,1 \mathrm{abcd}$ & $9,7 \mathrm{ab}$ & $18,7 \mathrm{abc}$ & 0,0 \\
Montana M3 & $62,8 \mathrm{~d}$ & $9,7 \mathrm{ab}$ & $17,1 \mathrm{abc}$ & 0,0 \\
\hline
\end{tabular}

*Médias seguidas da mesma letra na coluna não diferem significativamente entre si a $5 \%$ de probabilidade pelo teste de Tukey.

Mercedes. As outras cultivares foram menos afetadas, possivelmente pela alta cerosidade das folhas.

Se para as características de desenvolvimento vegetativo não houve muita diferença entre os tratamentos, a precocidade de bulbificação variou bastante conforme as cultivares e tipo de muda utilizada. A cultivar Mercedes, um híbrido de dias curtos adaptado a condições tropicais, com ciclo de 140 a 150 dias, apresentou alta porcentagem de bulbos em fase de 'enchimento' 84 dias após o transplante. Neste híbrido, nos tratamentos M1, M2 e M3, observou-se $54,6 \%, 38,3 \%$ e $35,2 \%$, respectivamente, de plantas bulbificadas, enquanto que, entre as demais cultivares, somente a cultivar Bola Precoce M1, apresentava $7,4 \%$ de bulbos no mesmo estádio (Tabela 3).

O diferencial na precocidade de bulbificação refletiu igualmente na colheita, observando-se diferença na maturação dos bulbos entre as cultivares, assim como para uma mesma cultivar, em relação ao tipo de muda empregado. Os bulbos foram colhidos quan- 
Tabela 4. Porcentagem de plantas de cebola com estalo e haste floral e após a colheita e cura dos bulbos, rendimento, peso médio do bulbo e porcentagem de bulbos nas classes 3C $(60<\varnothing<70 \mathrm{~mm})$ e $4(70<\varnothing<90 \mathrm{~mm})$. Ponta Grossa, UEPG, 2004.

\begin{tabular}{|c|c|c|c|c|c|c|}
\hline Tratamentos & Estalo (\%) & Haste floral (\%) & $\begin{array}{l}\text { Rend. Bulbos } \\
\left(\mathrm{t} \mathrm{ha} \mathrm{h}^{-1}\right)\end{array}$ & $\begin{array}{l}\text { Peso médio do } \\
\text { bulbo }(\mathrm{g})\end{array}$ & Classe 3C5 (\%) & Classe $45(\%)$ \\
\hline Mercedes M11 & 92,0 a & $0,0 \mathrm{~d}$ & $111,6 a b$ & $178,2 a b$ & $34,1 \mathrm{bc}$ & $43,5 b c$ \\
\hline Mercedes M21 & $85,9 a b$ & $0,0 \mathrm{~d}$ & $85,6 \mathrm{cde}$ & 135,4 cdef & $39,0 a b c$ & 22,2 cde \\
\hline Mercedes M32 & 91,2 a & $0,0 \mathrm{~d}$ & $71,9 \mathrm{de}$ & 116,0 ef & $33,3 \mathrm{bc}$ & $4,30 \mathrm{e}$ \\
\hline B. Precoce M12 & $85,6 a b$ & $6,0 \mathrm{bcd}$ & $106,0 \mathrm{abc}$ & $167,5 \mathrm{abc}$ & $52,6 \mathrm{ab}$ & $39,1 \mathrm{bc}$ \\
\hline B. Precoce M22 & 84,0 abc & $1,1 \mathrm{~cd}$ & $83,5 \mathrm{de}$ & 130,4 def & $42,7 \mathrm{abc}$ & 16,7 cde \\
\hline B. Precoce M33 & 92,0 a & $2,7 \mathrm{~cd}$ & 77,7 de & 122,6 ef & $53,7 a b$ & $2,1 \mathrm{e}$ \\
\hline Crioula M13 & $67,0 \mathrm{bcd}$ & 21,2 a & 117,2 a & 187,2 a & $28,6 \mathrm{c}$ & 71,4 a \\
\hline Crioula M24 & $69,0 \mathrm{abcd}$ & $14,8 \mathrm{abc}$ & $88,9 \mathrm{cde}$ & 143,4 bcdef & 59,1 a & 26,9 cde \\
\hline Crioula M34 & $78,0 \mathrm{abcd}$ & $12,9 \mathrm{abcd}$ & $74,7 \mathrm{de}$ & 116,8 ef & $39,6 a b c$ & $7,3 \mathrm{de}$ \\
\hline Montana M13 & $58,3 \mathrm{~d}$ & 25,2 a & $106,0 \mathrm{abc}$ & $165,6 \mathrm{abcd}$ & 35,4 bc & $62,5 a b$ \\
\hline Montana M24 & $61,8 \mathrm{~cd}$ & $14,5 \mathrm{abc}$ & $94,0 \mathrm{bcd}$ & 148,5 bcde & $54,7 a b$ & $32,6 \mathrm{~cd}$ \\
\hline Montana M34 & $71,3 \mathrm{abcd}$ & $18,9 a b$ & $70,7 \mathrm{e}$ & $111,5 \mathrm{f}$ & $46,2 \mathrm{abc}$ & $7,3 \mathrm{de}$ \\
\hline
\end{tabular}

* Médias seguidas da mesma letra minúscula na coluna não diferem significativamente entre si a 5\% de probabilidade pelo teste de Tukey; 1/Colheita realizada 113 dias após o transplante (DAP); ${ }^{2} /$ Colheita realizada 123 DAP; ${ }^{3 / C o l h e i t a ~ r e a l i z a d a ~} 132$ DAP; ${ }^{4} / \mathrm{Colheita}$ realizada 145 DAP; $5 /$ Porcentagem em relação ao número de bulbos na classe em relação ao número total de bulbos.

do apresentavam estalo acima de $80 \%$ para a maioria dos tratamentos (Tabela 4). As parcelas de Crioula e Montana, colhidas abaixo desse percentual, apresentavam bulbos formados com a película externa seca. No entanto, apresentavam a região do colo mais engrossada e sem indício de amolecimento. Além disso, algumas plantas apresentavam florescimento prematuro.

Um dos fatores que pode ter contribuído para o prolongamento do desenvolvimento vegetativo de algumas cultivares foi o cultivo na palha, que propicia maior retenção de umidade no solo e menor variação térmica na temperatura do solo (Amado et al., 1990), em decorrência da presença da cobertura. A presença da palha associada às altas precipitações que ocorreram principalmente em outubro e novembro $(441,1 \mathrm{~mm})$, estimularam o processo vegetativo e dificultaram o processo de maturação dos bulbos dos tratamentos mais tardios.

A maior precocidade de colheita foi observada nos tratamentos Mercedes M1 e M2, com respectivamente $92,1 \%$ e $85,9 \%$ de estalo 113 dias após o transplante (DAP), enquanto M3 apresentava, nessa data, 64,1\%. Este tratamento foi colhido 123 DAP com 91,2\% de estalo. Na mesma data foram colhidos os tratamentos Bola Precoce M1 e M2. Os tratamentos Bola Precoce M3, Crioula M1 e Montana M1 foram colhidos 132 DAP, com $92,0 \%, 67,0 \%$ e $58,3 \%$ de estalo, respectivamente. Já os tratamentos Crioula M2 e M3 e Montana M2 e M3 foram colhidos 145 DAP, com $69,0 \%, 78,0 \%, 61,8 \%$ e $71,3 \%$, respectivamente (Tabela 4). As cultivares Mercedes e Bola Precoce apresentaram na colheita, ótima maturação de bulbos, com alta porcentagem de estalo, característica altamente desejável, o que demonstra adaptabilidade ao local, à época e ao sistema de cultivo empregado.

Entre os tipos de mudas, observouse que mudas M1 e M2 propiciaram maturação mais precoce para a maioria das cultivares. Em M3, a maturidade foi mais tardia, acompanhando as características anteriormente apresentadas durante o desenvolvimento vegetativo, tais como altura, número de folhas e início de bulbificação. O tamanho da muda condicionou o desenvolvimento diferenciado das plantas no campo. Quanto maior a muda, maior foi o desenvolvimento vegetativo e mais precoce a bulbificação e a maturidade dos bulbos, traduzida pela ocorrência mais rápida do estalo.

O fator determinante da colheita de Crioula e de Montana com percentual menor de estalo foi a ocorrência de florescimento prematuro no final de ciclo (Tabela 4). Nessa condição, a planta emite a haste floral antes da completa maturação, o que é desfavorável para a maturação. Na região Sul do Brasil, o florescimento prematuro pode representar um grande problema para a produ- ção de bulbos, porque o início da bulbificação coincide com a primavera, quando freqüentemente ocorrem frentes frias que, diminuindo a temperatura, podem induzir as plantas ao florescimento prematuro.

Além da temperatura baixa, outros fatores como cultivar e tipo de muda são também considerados importantes na ocorrência de florescimento prematuro. As cultivares Crioula e Montana, quando plantadas com mudas do tipo M1 (bandejas de 128 células) apresentaram 21,2 e $25,3 \%$ de florescimento prematuro, respectivamente, um índice considerado bastante alto. A cultivar Bola Precoce apresentou percentuais mais baixos, independente do tipo de muda, enquanto a cultivar Mercedes não apresentou sequer florescimento (Tabela 4), o que é uma característica muito favorável.

O florescimento precoce pode ser evitado também através de um cronograma adequado de plantio. Quanto mais se antecipar o plantio das cultivares Crioula e Montana, maior será o risco de florescimento prematuro. Entretanto, nas condições de Santa Catarina, a cultivar Crioula apresenta florescimento prematuro inferior a $2 \%$ e, Bola Precoce, inferior a 1\% (Gandin et al., 2001). Embora nas condições deste experimento, as cultivares Crioula e Montana tenham apresentado florescimento prematuro, o rendimento e a qualidade dos bulbos não foram 
prejudicados severamente, já que o florescimento ocorreu no final de ciclo. Das cultivares avaliadas, somente a cultivar Montana não é utilizada comercialmente no Paraná. Pelos resultados observados, esta cultivar mostrou-se muito semelhante à cultivar Crioula, inclusive nas características do bulbo, quanto ao formato, coloração da película e alta produtividade.

As mudas provenientes de bandejas promoveram alta uniformidade de desenvolvimento. A porcentagem média de plantas que atingiram ponto de colheita foi de $98,3 \%$, praticamente a totalidade das mudas transplantadas. $\mathrm{O}$ grande vigor vegetativo observado através de características como altura, número de folhas, diâmetro do pseudocaule (Tabela 3), além do período longo de desenvolvimento das plantas, resultaram no final do cultivo em valores altamente expressivos no rendimento de bulbos (Tabela 4). A média de rendimento obtida, 90,7 t ha-1, quando comparada à média brasileira, 17,0 $\mathrm{t} \mathrm{ha}^{-1}$ (Costa et al., 2002), demonstra o quanto é possível evoluir em produtividade. Embora a produção de mudas em bandejas redunde em maior custo, os benefícios em termos de produtividade e qualidade do produto obtido demonstram que a tecnologia é competitiva. Além disso, existem alternativas para a diminuição do custo da produção de mudas em bandejas, através do uso de substratos alternativos.

Mudas maiores (M1), produzidas em bandejas de 128 células, propiciaram superioridade significativa no rendimento de bulbos em relação às mudas produzidas em bandejas de 200 e 288 células para as cultivares Mercedes, Bola Precoce e Crioula e, em relação a mudas produzidas em bandejas de 288 células para a cultivar Montana (Tabela 4). Dessa forma, o tamanho maior da muda foi um importante atributo na definição da sua qualidade, repercutindo posteriormente na precocidade de bulbificação, no maior rendimento e na qualidade dos bulbos. Na Coréia, Lee et al. (2000) observaram que em volumes maiores de células (bandejas de 72 e 128), as mudas foram maiores e também a a produção de bulbos, de 125,0 e 120,8 $\mathrm{t} \mathrm{ha}^{-1}$, respectivamente. Mettananda \& Fordham (1999) observaram que o tamanho da muda de cebola, avaliado em termos de número de folhas e peso, afetou o tamanho da planta até a maturidade.

De forma geral, não foram observadas diferenças significativas entre os tratamentos M2 e M3, exceto na cultivar Montana (Tabela 4). Esses resultados indicam que, quando a opção for prioritariamente pela produção de um grande número de mudas, a produção de mudas em bandeja de 288 células é vantajosa sobre a utilização de bandejas de 200 células, justamente pelo maior rendimento em quantidade de mudas. Em cebola, cujo cultivo no campo é com estande alto, Fontes \& Silva (2002) apontam que devem ser preferidas as bandejas de pelo menos 288 células.

Um dos componentes que contribuiu para a boa produtividade alcançada pelos diversos tratamentos foi o excelente tamanho dos bulbos. O peso médio dos bulbos no experimento, para todos os tratamentos, foi de $144 \mathrm{~g}$. Este resultado corrobora aqueles obtidos para as demais características, comprovando a alta qualidade das mudas provenientes de bandejas.

A classificação dos bulbos segundo a classe de tamanho (Tabela 4) é outro indicador da alta qualidade de produção alcançada. Não houve produção de bulbos não comerciais ou menores que bulbos da classe 2 (diâmetro menor que 35 $\mathrm{mm}$ ). A percentagem de bulbos menores que $50 \mathrm{~mm}$ (classe 2) foi muito baixa, exceto para a cultivar Mercedes, com mudas M2 e M3, em que os percentuais de bulbos com diâmetro inferior a 50 mm foi de 12,6 e $19,3 \%$, respectivamente. Ao contrário, destacaram-se as cultivares Crioula e Montana, em ambos os casos com mudas M1 e M2, cujos bulbos tiveram calibre sempre superior. $\mathrm{Na}$ classe 3C, bulbos de diâmetro entre 60 e $70 \mathrm{~mm}$, foram observados percentuais acima de 50\% nos tratamentos Crioula M2, Montana M2 e Bola Precoce M3 e M1. No entanto, esses tratamentos diferiram significativamente somente de Crioula M1, que apresentou o menor percentual de bulbos na classe $3 \mathrm{C}$ $(28,6 \%)$ (Tabela 4). A cultivar Crioula, com mudas produzidas em bandejas de 128 células, destacou-se significativamente de todos os demais tratamentos, exceto Montana M1, pelo alto percentual $(71,4 \%)$ de bulbos da classe 4, ou seja, bulbos com diâmetro entre 70 e $90 \mathrm{~mm}$. O tamanho maior da muda usada no transplante, as características de grande vigor durante o crescimento da planta e o período longo de desenvolvimento resultaram em alta produtividade e qualidade dos bulbos.

As cultivares nos tratamentos M1 tiveram sua produção concentrada em bulbos tipicamente graúdos, dos tipos $3 \mathrm{C}$ e 4 , justamente as classes preferidas pelo mercado consumidor nacional (Silva et al.,1991). Somando-se os valores, as duas classes juntas correspondem a $100 \%$ da produção da cultivar Crioula, $97,9 \%$ da produção da cultivar Montana, 91,7\% da produção da cultivar Bola Precoce e 77,6\% da produção da cultivar Mercedes.

Nos tratamentos M2, a cultivar Crioula apresentou $86,0 \%$ de sua produção incluída nas classes $3 \mathrm{C}$ e 4 , a cultivar Montana apresentou 87,3\%, a cultivar Bola Precoce, 59,4 e, a cultivar Mercedes, 61,2\%. As cultivares Crioula e Montana apresentaram altos percentuais da produção incluídas nas classes superiores de bulbos, tanto para mudas M1, quanto para mudas M2. A cultivar Bola Precoce teve uma diminuição sensível na classificação de bulbos quando passou-se de mudas M1 para mudas M2. Já, a cultivar Mercedes teve comportamento semelhante tanto para mudas M1 quanto para M2.

A cultivar Mercedes foi a que apresentou os menores percentuais de produção nas classes 3C e 4 e a única a apresentar bulbos na classe 2. Possivelmente, a ocorrência de míldio, com a diminuição de sua área foliar afetou o rendimento de bulbos deste material. O míldio é uma das principais doenças da cebola no sul do Brasil, com altos riscos de perdas, tanto na fase de canteiro como na lavoura, em pós-transplante (Boff, 1996).

Independentemente da cultivar e do número de células, a produção de mudas de cebola em bandejas, mostrou ser um técnica eficiente, apresentando alta produtividade e excelente qualidade de bulbos. Os resultados obtidos com a produção de mudas em bandejas podem contribuir para aumentar decisivamente a baixa produtividade média do Estado, de 10,7 t ha-1 (Resende et al., 2002). 


\section{REFERÊNCIAS}

AMADO TJC; MATOS AT; TORRES L. 1990. Flutuação da temperatura e umidade do solo sob preparo convencional e em faixas na cultura da cebola. Pesquisa Agropecuária Brasileira 25: 625-631.

BARROS SBM de. 1997. Avaliação de diferentes recipientes na produção de mudas de tomate (Lycopersicon esculentum Mill) e pepino (Cucumis sativus L.). Piracicaba: USPESALQ. 70p (Tese mestrado).

BOEING G. 2002. Fatores que afetam a qualidade da cebola na agricultura familiar catarinense. Florianópolis: Instituto CEPA/SC. 80p.

BOFF P. 1996. Levantamento de doenças na cultura da cebola, em Santa Catarina. Fitopatologia Brasileira 21: 110-114.

CARDOSO AII; COSTA CP. 1999. Production of onion bulb sets in styrofoam trays. Scientia Agricola 56: 969-974.

COSTA ND; LEITE DL; SANTOS CAF; CANDEIA JA; VIDIGAL SM. 2002. Cultivares de cebola. Informe Agropecuário 23: 20-27.

DELLACECCA V; LOVATO AFS; STOFFELLA PJ; CANTLIFFE DJ; DAMATO G. 2000. Effects of different plant densities and planting systems on onion (Allium cepa $\mathrm{L}$.) bulb quality and yield. Acta Horticulturae 533: 197-203.

EMBRAPA. 1999. Sistema Brasileiro de Classificação de Solos. Rio de Janeiro: Embrapa Solos. 412p.

EPAGRI. 1995. Pesquisa testa novas técnicas para produção de mudas de cebola. Agropecuária Catarinense 8: 25-28.
FONTES PCR; SILVA DJH. 2002. Métodos de produção de cebola. Informe Agropecuário 23: 28-35.

GANDIN CL; GUIMARÃES DR; THOMAZELLI LF; BOEING G. 2001. Escolha da cultivar adequada para produção de cebola. Agropecuária Catarinense 14: 45-48.

HERISON C; MASABNI JG; ZANDSTRA BH. 1993. Increasing seedling density, age, and nitrogen fertilization increases onion yield. HortScience 28: 23-25.

JAIME M; ROBERTS L; MC DONALD MR. 2001. Growing onion transplants in plug trays. Ministry of Agriculture and Food. Disponível em http://www.gov.on.ca/OMAF/english/ crops/facts/01-019.htm. Acessado em 07 de outubro de 2004.

LATIMER JG. 1991. Container size and shape influence growth and landscape performance of marigold seedling. HortScience 26: 124 126.

LEE JS; SEONG KC; SIN YA; RO HM; UM YC. 2000. Introduction of spring cultivation of onions by adapting the plug seedling system in the middle region of Korean peninsula. Korean Journal of Horticultural Science and Technology 18: 9-13.

LESKOVAR DI; VAVRINA CS. 1999. Onion growth and yield are infuenced by transplant tray cell size and age. Scientia Horticulturae 80: 133-143.

METTANANDA KA; FORDHAM R. 1999. The effects of plant size and leaf number on the bulbing of tropical short-day onion cultivars (Allium cepa L.) under controlled environments in the United Kingdom and tropical field conditions in Sri Lanka. Journal of Horticultural Science \& Biotechnology 74: 622-631.
MINAMI K. 1995. Produção de mudas de alta qualidade em Horticultura. São Paulo: Ceres. $357 \mathrm{p}$.

MODOLO VA; TESSARIOLI NETO J. 1998. Avaliação do desenvolvimento de mudas de quiabeiro (Abelmoschus esculentus (L.) Moench) em diferentes tipos de bandejas e substrato. In: CONGRESSO BRASILEIRO DE OLERICULTURA. Anais... Petrolina: SOB (CD-ROM).

RESENDE LMA; MASCARENHAS MHT; SIMÃO MLR. 2002. Panorama da produção e da comercialização da cebola em Minas Gerais. Informe Agropecuário 23: 7-19.

RESENDE GM de; YURI JE; MOTA JR; SOUZA R de; FREITAS SAC de; RODRIGUES JUNIOR JC. 2003. Efeitos de tipos de bandejas e idade de transplantio de mudas sobre o desenvolvimento e produtividade da alface americana. Horticultura Brasileira 21: 558562.

REGHIN MY; OTTO RF; VINNE J van der. 2004. Efeito da densidade de mudas por célula e do volume da célula na produção de mudas e cultivo da rúcula. Ciência e Agrotecnologia 28: 289-297.

SEAB/DERAL. 2002. Valor Bruto da Agropecuária Paranaense. Disponível em http:/ www.pr.govbr/seab/deral. Acessado em 03 outubro de 2004.

SILVA E; TEIXEIRA LAJ; AMADO TJC. 1991. The increase in onion production in Santa Catarina State, South of Brazil. Onion Newsletter for the tropics 3: 7-9.

VINCENZO MCV de; TESSARIOLI NETO J. 2003. Onion seedling production in styrofoam trays under controlled environment, as summer-planted onions. Scientia Agricola 60: 65-69. 